\title{
In Vitro Effect of Soy Isoflavone and Equol on Soluble CD40L Release Stimulated by Ristocetin in Platelets from Postmenopause Women
}

\author{
Natalia Gonzalez, Argelia Garrido, Ingrid Acevedo, Luis Valladares* \\ Institute of Nutrition and Food Technology, Universidad de Chile, Santiago, Chile \\ Email:
}

Received 20 December 2014; accepted 5 January 2015; published 16 January 2015

Copyright (C) 2015 by authors and Scientific Research Publishing Inc.

This work is licensed under the Creative Commons Attribution International License (CC BY). http://creativecommons.org/licenses/by/4.0/

(c) (i) Open Access

\section{Abstract}

The inhibition of specific flavonoid on the in vitro platelet aggregation induced by collagen, arachidonic acid and thromboxane A2 (TxA2) agonist, seems to be related mostly to their ability to compete for binding to the TxA2 receptor (TP). The aim of this study was to analyze the effect of soy isoflavone and equol in terms of inhibiting the platelet aggregation and SCD40L release stimulated by ristocetin, an in vitro-activator of glycoprotein $\mathrm{Ib} / \mathrm{IX} / \mathrm{V}$, in platelets from postmenopausal women. When platelets were stimulated by $0.75 \mathrm{mg} / \mathrm{ml}$ ristocetin, equol $(10 \mu \mathrm{M})$ exhibited a greater inhibitory activity on platelet aggregation $(\sim 68 \%)$ than genistein or daidzein. The effect of equol was dependent on the concentration of platelet aggregation agonist. In the presence of ristocetin $(0.75 \mathrm{mg} / \mathrm{ml}, 1.125 \mathrm{mg} / \mathrm{ml}$ and $1.5 \mathrm{mg} / \mathrm{ml})$, the inhibitory effect of $10 \mu \mathrm{M}$ equol was $68 \% \pm$ $5 \%, 54 \% \pm 4 \%$ and $31 \% \pm 5 \%$, respectively. Equol $(10 \mu \mathrm{M})$ was a potent inhibitor $(\sim 35 \%)$ of sCD40L release when stimulated with $1.5 \mathrm{mg} / \mathrm{ml}$ ristocetin. However, no significant differences were noted in platelets incubated in the presence of genistein or daidzein and stimulated by ristocetin. On the other hand, SQ29548, a high TP antagonist, also inhibited the SCD40L release stimulated by ristocetin. Finally, $10 \mu \mathrm{M}$ of genistein, daidzein or equol did not significantly affect the thromboxane $B_{2}$ production when platelets were incubated with $1.5 \mathrm{mg} / \mathrm{ml}$ ristocetin. The relevance of this study was to find that equol exhibits a potent activity by inhibiting ristocetin-induced sCD40L release, suggesting that soy isoflavone has important biological effects on the hemostatic system. However, clinical trials will be necessary to assess the effect of equol on platelet and their impact on inflammatory markers.

\footnotetext{
${ }^{*}$ Corresponding author.
}

How to cite this paper: Gonzalez, N., Garrido, A., Acevedo, I. and Valladares, L. (2015) In Vitro Effect of Soy Isoflavone and Equol on Soluble CD40L Release Stimulated by Ristocetin in Platelets from Postmenopause Women. J. Biomedical Science and Engineering, 8, 24-30. http://dx.doi.org/10.4236/ibise.2015.81002 


\section{Keywords}

\section{Platelet, sCD40L, Phyoestrogen, Isoflavone, Equol}

\section{Introduction}

The bean of soy produces isoflavones, principally, genistein, daidzein and glycitein. Also, daidzein is metabolized by intestinal microbiota and transformed into equol. Isoflavones have been suggested as the principal chemical constituents responsible for the potential preventive effect of soy bean against risk factor of hormonerelated diseases and cardiovascular disease (CVD) [1] [2]. Different mechanisms have been proposed for the activity of isoflavones against risk factor of CVD, including estrogen-like effects, prevention of oxidative LDL and anti-platelets aggregation [3] [4].

Platelets initially interact with the sub endothelium via adhesive receptors such as glycoprotein Ib/IX/V receptors, which mediate rolling and tethering of the platelets to von Willebrand factor on the sites of vascular injury and induce glycoprotein IIb/IIIa activation, resulting in platelet aggregation [5]. Platelet adhesion and aggregation at the site of plaque rupture is a crucial event in thrombus formation and in the development of acute coronary syndrome [6]. Thus, platelets play a key role in the process of athero-thrombosis via release of inflammatory and pro-thrombotic molecules such as reactive oxidant species, P-selectin and soluble CD40 ligand (sCD40L) [7]. The interaction of von Willebrand factor-glycoprotein Ib/IX/V is known to be induced by ristocetin, an in vitro activator of glycoprotein Ib/IX/V [8]. Recently, Enomoto et al. demonstrated that ristocetin stimulate the release of sCD40L from human platelets through $\mathrm{TXA}_{2}$-mediated activation of TP [9]. On the other side, we and other groups have shown that soy isoflavone compete for binding to TP in human platelets [10] [11].

In the present study, we analyzed the effect of genistein, daidzein and equol in the action of ristocetin release of sCD40L from platelets of postmenopausal women. In addition, the effect of isoflavone and equol on ristocetinstimulated platelets aggregation was examined to provide the antiplatelet effect.

\section{Materials and Methods}

The study protocol was reviewed and approved by the Institutional Review Board for Research on Human Subjects of the Institute of Nutrition and Food Technology, University of Chile.

\subsection{Subjects}

Twenty-five women, aged 40 - 60 years, were recruited from Santiago Metropolitan Area, and gave informed consent according to the Declaration of Helsinki. To be eligible for this study, women had to be in menopause at least 6 months, have FSH levels over $20 \mathrm{IU} / \mathrm{L}$, without any type of hormonal treatment during previous 6 months, and not currently using soybean-derived products, or herbal supplement diets. Exclusion criteria included: cigarettes smoking within the last 5 years, diabetes, heavy alcohol consumption (more $30 \mathrm{~g} /$ day), hypertension and coexistent major illnesses.

\subsection{Materials}

Genistein, daizein and ristocetin were purchased from Sigma-Aldrich Co. (St. Louis, MA, USA). Equol was obtained from Cayman Chemical, Co. (Ann Arbor, MI, USA). The other materials and chemicals were obtained from commercial sources.

\subsection{Preparation of Platelets and Aggregation Assay}

Human platelets were prepared as previously described [12]. In brief, blood from donors was collected by venipuncture into sodium citrate (9:1) and centrifuge at $200 \times \mathrm{g}$ for $15 \mathrm{~min}$ at $25^{\circ} \mathrm{C}$ to prepare platelets-rich plasma (PRP). Platelets-poor plasma (PPP) was prepared from blood by centrifugation at $2500 \mathrm{~g}$ for $5 \mathrm{~min}$.

A turbidimetric method was applied to measure platelet aggregation, using a Lumi-aggregometer (Chrono-log 
Corp, Havertown, PA, USA). Platelet suspensions $(0.25 \mathrm{ml})$ were preincubated with various concentrations of genistein, daidzein, equol or an isovolumetric solvent control (0.5\% DMSO) for 15 min before the addition of ristocetin. The reaction was allowed to proceed for $6 \mathrm{~min}$, and the extent of aggregation was expressed in lighttransmission units. The percentage of transmittance of the isolated platelets was recorded as $0 \%$, and plateletpoor plasma (blank) was recorded as $100 \%$.

\subsection{Release of SCD40L}

The measurement of sCD40L was performed as described by Enomoto et al. [8]. In brief, PRP $\left(3.0 \times 10^{8} \mathrm{cells} / \mathrm{ml}\right)$ were preincubated with different concentration of genistein, daidzein, equol or a solvent control (0.5\% DMSO) for $15 \mathrm{~min}$ at $37^{\circ} \mathrm{C}$ and then stimulated by vehicle (0.5\% DMSO) or $1.5 \mathrm{mg} / \mathrm{ml}$ of ristocetin for 30 min with constant stirring of $800 \mathrm{rpm}$. Platelet incubation was ended by the addition of ice-cold $10 \mathrm{mM}$ EDTA. The PRP mixture was centrifuged at $20,000 \times \mathrm{g}$ for $2 \mathrm{~min}$ at $4^{\circ} \mathrm{C}$. Supernatants were removed and store at $-80^{\circ} \mathrm{C}$. Soluble CD40L levels were determined using a Human sCD40-Ligand Quantikine kit (R \& D systems, Minneapolis, MN).

\subsection{Statistical Analysis}

Values shown in the text, tables, and figures are means \pm SD. One way ANOVA test was applied for comparisons of means, and then Student's t test was performed. $\mathrm{p}<0.05$ was considered significant.

\section{Results}

\subsection{Effect of Isoflavone on Ristocetin Induced Platelet Aggregation}

In a preliminary assay, we first tested the inhibitory capacity of genistein, daidzein and equol $(10 \mu \mathrm{M})$ on platelets aggregation induced by $0.75 \mathrm{mg} / \mathrm{ml}$ ristocetin. As observed in Figure 1, the three isoflavones inhibited platelet aggregation, but equol exhibited the most potent inhibitory activity of platelet aggregation. The half maximal inhibitory concentration of equol for platelet aggregation stimulated by $0.75 \mathrm{mg} / \mathrm{ml}$ ristocetin, was approximately $8 \mu \mathrm{M}$ (Figure 2). The solvent control (DMSO, 0.5\%) did not significantly affect platelet aggregation stimulated by the agonist. The inhibitory effect of equol was dependent on the concentration of platelet aggregation agonist. In presence of ristocetin $(0.75 \mathrm{mg} / \mathrm{ml}, 1.125 \mathrm{mg} / \mathrm{ml}$ and $1.5 \mathrm{mg} / \mathrm{ml})$, the inhibitory effect of $10 \mu \mathrm{M}$ equol was $68 \% \pm 5 \%(\mathrm{p}<0.01), 54 \% \pm 4 \%(\mathrm{p}<0.02)$ and $31 \% \pm 5 \%(\mathrm{p}<0.03)$ respectively.

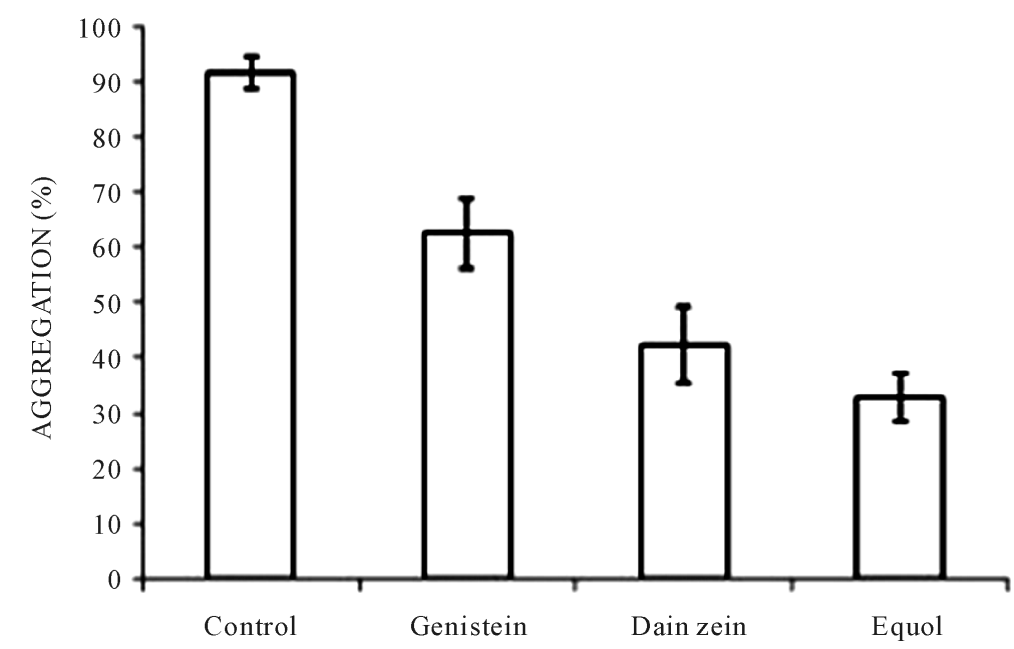

Figure 1. Effect of soy isoflavone and equol on platelet aggregation induced by ristocetin. Platelet $\left(3 \times 10^{8}\right.$ platelets $\left./ \mathrm{ml}\right)$ from postmenopause women were preincubated $\left(15 \mathrm{~min}, 37^{\circ} \mathrm{C}\right)$ with $10 \mu \mathrm{M}$ of genistein, daidzein, equol or the solvent control ( $0.5 \%$ DMSO) followed by the addition of ristocetin $(0.75 \mathrm{mg} / \mathrm{ml})$ to trigger platelet aggregation. Data are present as the mean \pm SD $(n=8)$. Mean values were significantly different from control value: $\mathrm{p}<$ 0.001 . 


\subsection{Effect of Genistein, Daidzein, Equol and SQ29548 on Ristocetin Induced SCD40L Release from Platelets}

When was analyzed the effect of $10 \mu \mathrm{M}$ isoflavone on sCD40L release reaction stimulated by $1.5 \mathrm{mg} / \mathrm{mL}$ of ristocetin (Table 1 ), equol exhibited a potent inhibitory activity ( 35\%). Ristocetin-stimulated sCD40L release from platelets was clearly inhibited by $10 \mu \mathrm{M}$ SQ29548 ( 79\%) a TP antagonist. However, no significant differences were noted in platelet incubated in the presence of genistein or daidzein and stimulated by ristocetin. Also, when platelets were incubated with a higher concentration of equol $(30 \mu \mathrm{M})$ and stimulated by ristocetin (1.5 mg/mL), no significant differences were found between the inhibition observed with $10 \mu \mathrm{M}$ and $30 \mu \mathrm{M}$ equol. Preincubation of platelets with $10 \mu \mathrm{M}$ of genistein, daidzein or equol, did not significantly modified basal sCD40L release reaction (data not shown).

\subsection{Effects of Isoflavone and Equol on Ristocetin-Induced TXA Formation from Platelets}

Ristocetin $(1.5 \mathrm{mg} / \mathrm{mL})$ induces a marked increase in $\mathrm{TXB}_{2}$ compared to control $(0.80 \pm 0.21$ vs. $2.79 \pm 0.61$ $\mathrm{ng} / \mathrm{ml} \mathrm{n}=12$ ). However, $10 \mu \mathrm{M}$ genistein, daidzein or equol did not affect significantly TxB2 stimulated by

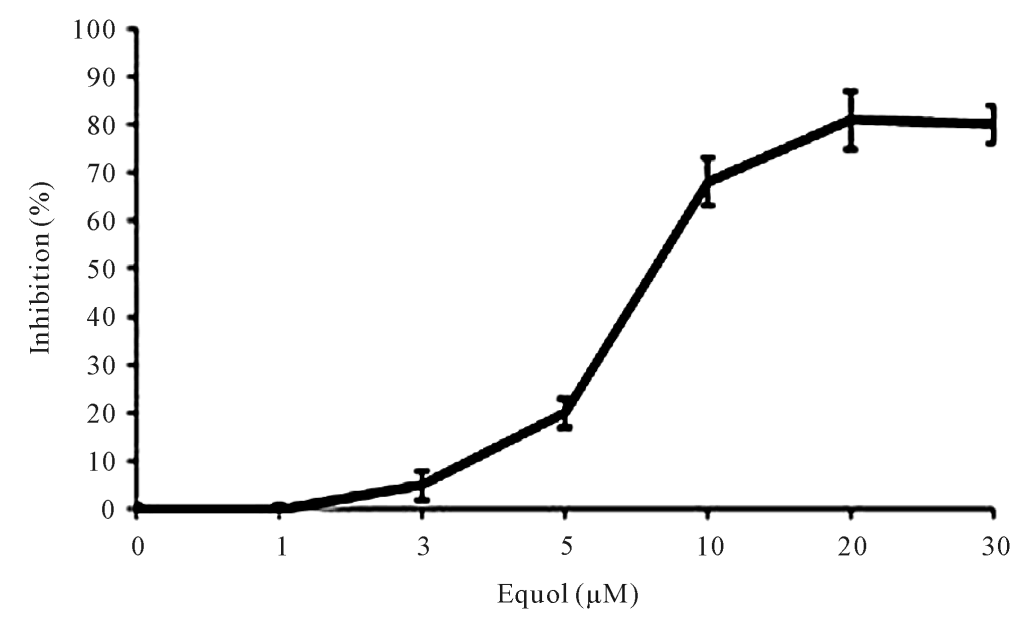

Figure 2. Inhibitory effect of equol on platelet stimulated by ristocetin. Platelets $\left(3 \times 10^{8}\right.$ platelets $\left./ \mathrm{ml}\right)$ were preincubated $\left(15 \mathrm{~min}, 37^{\circ} \mathrm{C}\right)$ with equol $(1-10 \mu \mathrm{M})$ or the solvent control $(0.5 \%$ DMSO) followed by the addition of ristocetin $(0.75-1.5 \mathrm{mg} / \mathrm{ml})$ to trigger platelets aggregation. Data are presented as the mean $\pm \operatorname{SD}(n=6)$.

Table 1. Effect of isoflavone and SQ29548 on ristocetin induced SCD40L release from platelets $\left(3 \times 10^{8}\right.$ per ml). Platelets were preincubated (15 min, $37^{\circ} \mathrm{C}$ ) with $10 \mu \mathrm{M}$ of genistein, daidzein, equol, SQ29548 (TP antagonist) or the solvent control ( $0.5 \%$ DMSO) followed by the addition of $1.5 \mathrm{mg} / \mathrm{ml}$ of ristocetin for $30 \mathrm{~min}$ to trigger SCD40L.

\begin{tabular}{cc}
\hline Condition & $\begin{array}{c}\text { sCD40L, ng/mL } \\
\text { Mean } \pm \text { SD, N=6 }\end{array}$ \\
\hline Basal & $0.38 \pm 0.13$ \\
Ristocetin & $4.86 \pm 0.63$ \\
Ristocetin + Genistein & $4.71 \pm 0.57$ \\
Ristocetin + Daidzein & $4.81 \pm 0.51$ \\
Ristocetin + Equol & $3.20 \pm 0.32^{*}$ \\
Ristocetin + SQ29548 & $0.95 \pm 0.21^{*}$ \\
\hline
\end{tabular}

${ }^{*} \mathrm{p}<0.001$ compared with ristocetin (control) condition. 
ristocetin; $2.85 \pm 0.42 \mathrm{ng} / \mathrm{ml}, 2.93 \pm 0.43 \mathrm{ng} / \mathrm{ml}$ and $2.76 \pm 0.31 \mathrm{ng} / \mathrm{ml}$, respectively.

\section{Discussion}

Besides the classic inflammatory markers, CD40L has been introduced as a new inflammatory marker. Studies on the cellular distribution of CD40L indicate that more than 95\% of the circulating CD40L exist in platelets. Platelets express CD40L on their surface upon stimulation, and CD40L is then cleaved and circulates as sCD40L. When expressed on the surface of platelets and exposed to CD40-bearing vascular cells, platelet-associated CD40L is capable of initiating various inflammatory responses [7] [13]. Increasing evidence shows that CD40CD40L interaction plays a crucial role in the pathogenesis of atherosclerosis and CVD [14]. Moreover, there is evidence that the SCD40L level is a strong predictor of cardiovascular risk [15].

The main interest of the present study was to investigate the effect of soy isoflavones and equol in terms of inhibiting the aggregation and SCD40L release stimulated by ristocetin on platelets from postmenopausal women. The results of these studies confirm that GPIb/IX/V activity induces sCD40L release from human platelets [9]. Additionally, our data demonstrated that equol exhibited a more potent activity at inhibiting ristocetin-induced platelet aggregation and sCD40L release than genistein and daidzein.

Under normal physiological conditions, platelets play a primary role in hemostasis through their aggregation. However, alteration of platelets activity regulation is an important factor in CVD and thrombosis. Evidence of platelets involvement in these pathologies includes increased TxA2 production and increased TP density [16] [17]. Interestingly, dietary flavonoids have a potential to affect platelet aggregation and function, although specific mechanisms by which this activation occurs has not been fully established [18].

Several studies, including ours, have demonstrated that inhibition of specific flavonoid of in vitro platelet aggregation induced by collagen, arachidonic acid and thromboxane A2 agonist, seems to be related, to a great extent, to their ability to compete for binding to the TP [10] [11] [19]. Moreover, we have demonstrated that equol is more active than genistein and daidzein to compete for binding to TP [10]. Interestigly, Enomoto et al. [9] showed that ristocetin induces TxA2 production, which leads to stimulation of the release of sCD40L from human platelets. Therefore, when studied the effect of soy isoflavone and equol on ristocetin-induced sCD40 ligand release via TxA2, the ristocetin-stimulated sCD40 ligand release from postmenopause women platelets was significantly inhibited when the platelets were pretreated with equol, but not with genistein or daidzein. Moreover, SQ29548, a highly TP antagonist, also inhibited the sCD40L release stimulated by ristocetin. On the other hand, equol did no affect TxB2 stimulated by ristocetin. Therefore, it is probable that equol inhibits sCD40L release through the competition for the binding to TP.

Soy-derived isoflavone have received wide attention because of its potential beneficial effects on chronic diseases, such as CVD [20] [21]. However, the results of the in vitro studies of these compounds and their relevance on human health can be controversial. The concentrations of soy isoflavones and equol necessary to elicit inhibitory in vitro activities observed in the present study $(10-30 \mu \mathrm{M})$ may reflect a pharmacological rather than physiological action. Clinical studies showed, after soy supplementation, that plasma genistein, daidzein and equol levels can reach $0.6 \mu \mathrm{M}, 0.5 \mu \mathrm{M}$ and $0.2 \mu \mathrm{M}$, respectively [22]. However, isoflavone and equol may accumulate in tissues, reaching concentrations much higher than those found in serum [23]. So, the potential health effect of soy and its isoflavones cannot be completely understood until their bioactivity has been fully established [24].

\section{Conclusion}

The present study shows new experimental evidence to the biological plausibility of the epidemiological finding that soy-isoflavones decreases CVD morbidity and mortality. The present finding, although preliminary, show that equol exhibits a potent activity by inhibiting ristocetin-induced SCD40L release, suggesting that soy isoflavone have biologically significant effects on the hemostatic system. However, clinical trials will be necessary to assess the effect of equol on platelet and their impact on inflammatory markers.

\section{Acknowledgements}

This work was supported by grant No 1100299 from National Fund for Scientific and Technological Development of Chile (FONDECYT), grant No ENL007/14 from Universidad de Chile. 


\section{References}

[1] Setchell, K.D. and Cassidy, A. (1990) Dietary Isoflavones: Biological Effects and Relevance to Human Health. Journal of Nutrition, 129, 758S-767S.

[2] Jackson, R.L., Greiwe, J.S. and Schwen, R.J. (2011) Emerging Evidence of the Health Benefits of S-Equol, an Estrogen Receptor $\beta$ Agonist. Nutrition Review, 69, 432-448. http://dx.doi.org/10.1111/j.1753-4887.2011.00400.x

[3] Cano, A., García-Pérez, M.A. and Tarín, J.J. (2010) Isoflavones and Cardiovascular Disease. Maturitas, 67, $219-226$. http://dx.doi.org/10.1016/j.maturitas.2010.07.015

[4] Siow, R.C. and Mann, G.E. (2010) Dietary Isoflavones and Vascular Protection: Activation of Cellular Antioxidant Defenses by SERMs or Hormesis? Molecular Aspects of Medicine, 31, 468-477. http://dx.doi.org/10.1016/j.mam.2010.09.003

[5] Li, Z., Delaney, M.K., O’Brien, K.A. and Du, X. (2010) Signaling during Platelet Adhesion and Activation. Arteriosclerosis, Thrombosis, and Vascular Biology, 30, 2341-2349. http://dx.doi.org/10.1161/ATVBAHA.110.207522

[6] Gawaz, M., Langer, H. and May, A.E. (2005) Platelets in Inflammation and Atherogenesis. The Journal of Clinical Investigation, 115, 3378-3384. http://dx.doi.org/10.1172/JCI27196

[7] Nurden, A.T. (2011) Platelets, Inflammation and Tissue Regeneration. Thrombosis and Haemostasis, 105, S13-S33. http://dx.doi.org/10.1160/THS10-11-0720

[8] Dong, J.F., Berndt, M.C., Schade, A., McIntire, L.V., Andrews, R.K. and López, J.A. (2001) Ristocetin-Dependent, but Not Botrocetin-Dependent, Binding of von Willebrand Factor to the Platelet Glycoprotein Ib-IX-V Complex Correlates with Shear-Dependent Interactions. Blood, 97,162-168. http://dx.doi.org/10.1182/blood.V97.1.162

[9] Enomoto, Y., Adachi, S., Matsushima-Nishiwaki, R., Doi, T., Niwa, M., Akamatsu, S., Tokuda, H., Ogura, S., Yoshimura, S., Iwama, T. and Kozawa, O. (2010) Thromboxane A2 Promotes Soluble CD40 Ligand Release from Human Platelets. Atherosclerosis, 209, 415-421. http://dx.doi.org/10.1016/j.atherosclerosis.2009.10.024

[10] Muñoz, Y., Garrido, A. and Valladares, L. (2009) Equol Is More Active than Soy Isoflavone Itself to Compete for Binding to Thromboxane A(2) Receptor in Human Platelets. Thrombosis Research, 123, 740-774. http://dx.doi.org/10.1016/j.thromres.2008.07.011

[11] Guerrero, J.A., Lozano, M.L., Castillo, J., Benavente-Garcia, O., Vicente, V. and Rivera, J. (2005) Flavonoids Inhibit Platelet Function through Binding to the Thromboxane A2 Receptor. The Journal of Thrombosis and Haemostasis, 3, 369-376. http://dx.doi.org/10.1111/j.1538-7836.2004.01099.x

[12] Garrido, A., Munoz, Y., Sierralta, W. and Valladares, L. (2012) Metabolism of Dehydroepiandrosterone Sulfate and EstroneSulfate by Human Platelets. Physiological Research, 61, 381-388.

[13] Schonbeck, U. and Libby, P. (2001) The CD40/CD154 Receptor/Ligand Dyad. Cellular and Molecular Life Sciences, 58, 4-43. http://dx.doi.org/10.1007/PL00000776

[14] Lievens, D., Zernecke, A., Seijkens, T., Soehnlein, O., Beckers, L., Munnix, I.C., Wijnands, E., Goossens, P., van Kruchten, R., Thevissen, L., Boon, L., Flavell, R.A., Noelle, R.J., Gerdes, N., Biessen, E.A., Daemen, M.J., Heemskerk, J.W., Weber, C. and Lutgens, E. (2010) Platelet CD40L Mediates Thrombotic and Inflammatory Processes in Atherosclerosis. Blood, 116, 4317-4327. http://dx.doi.org/10.1182/blood-2010-01-261206

[15] Derosa, G., D’Angelo, A., Mugellini, A., Pesce, R.M., Fogari, E. and Maffioli, P. (2012) Evaluation of Emerging Biomarkers in Cardiovascular Risk Stratification of Hypertensive Patients: A 2-Year Study. Current Medical Research and Opinion, 28, 1435-1445. http://dx.doi.org/10.1185/03007995.2012.717527

[16] Halushka, P.V., Mais, D.E., Mayeux, P.R. and Morinelli, T.A. (1989) Thromboxane, Prostaglandin and Leukotriene Receptors. Annual Review of Pharmacology and Toxicology, 29, 213-239. http://dx.doi.org/10.1146/annurev.pa.29.040189.001241

[17] Giannarelli, C., Zafar, M.U. and Badimon, J.J. (2010) Prostanoid and TP-Receptors in Atherothrombosis: Is There a Role for Their Antagonism? Thrombosis and Haemostasis, 104, 949-954. http://dx.doi.org/10.1160/TH10-03-0195

[18] Ostertag, L.M., O’Kennedy, N., Kroon, P.A., Duthie, G.G. and de Roos, B. (2010) Impact of Dietary Polyphenols on Human Platelet Function-A Critical Review of Controlled Dietary Intervention Studies. Molecular Nutrition \& Food Research, 54, 60-81. http://dx.doi.org/10.1002/mnfr.200900172

[19] Navarro-Núñez, L., Castillo, J., Lozano, M.L., Martínez, C., Benavente-García, O., Vicente, V. and Rivera, J. (2009) Thromboxane A2 Receptor Antagonism by Flavonoids: Structure-Activity Relationships. Journal of Agricultural and Food Chemistry, 57, 1589-1594. http://dx.doi.org/10.1021/jf803041k

[20] Sacks, F.M., Lichtenstein, A., Van Horn, L., Harris, W., Kris-Etherton, P. and Winston, M. (2006) Soy Protein, Isoflavones, and Cardiovascular Health: A Summary of a Statement for Professionals from the American Heart Association Nutrition Committee. Arteriosclerosis, Thrombosis, and Vascular Biology, 26, 1689-1692.

http://dx.doi.org/10.1161/01.ATV.0000227471.00284.ef 
[21] Xiao, C.W. (2008) Health Effects of Soy Protein and Isoflavones in Humans. Journal of Nutrition, 138, 12445-12495.

[22] Zubik, L. and Meydani, M. (2003) Bioavailability of Soybean Isoflavones from Aglycone and Glucoside Forms in American Women. The American Journal of Clinical Nutrition, 77, 1459-1465.

[23] Bolca, S., Urpi-Sarda, M., Blondeel, P., Roche, N., Vanhaecke, L., Possemiers, S., Al-Maharik, N., Botting, N., De Keukeleire, D., Bracke, M., Heyerick, A., Manach, C. and Depypere, H. (2010) Disposition of Soy Isoflavones in Normal Human Breast Tissue. The American Journal of Clinical Nutrition, 91, 976-984. http://dx.doi.org/10.3945/ajcn.2009.28854

[24] Larkin, T., Price, W.E. and Astheimer, L. (2008) The Key Importance of Soy Isoflavone Bioavailability to Understanding Health Benefits. Critical Reviews in Food Science and Nutrition, 48, 538-552. http://dx.doi.org/10.1080/10408390701542716 
Scientific Research Publishing (SCIRP) is one of the largest Open Access journal publishers. It is currently publishing more than 200 open access, online, peer-reviewed journals covering a wide range of academic disciplines. SCIRP serves the worldwide academic communities and contributes to the progress and application of science with its publication.

Other selected journals from SCIRP are listed as below. Submit your manuscript to us via either submit@scirp.org or Online Submission Portal.
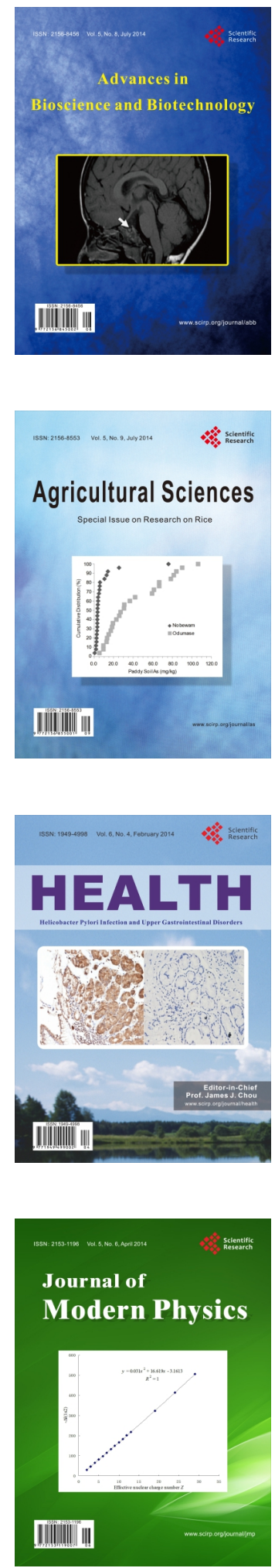
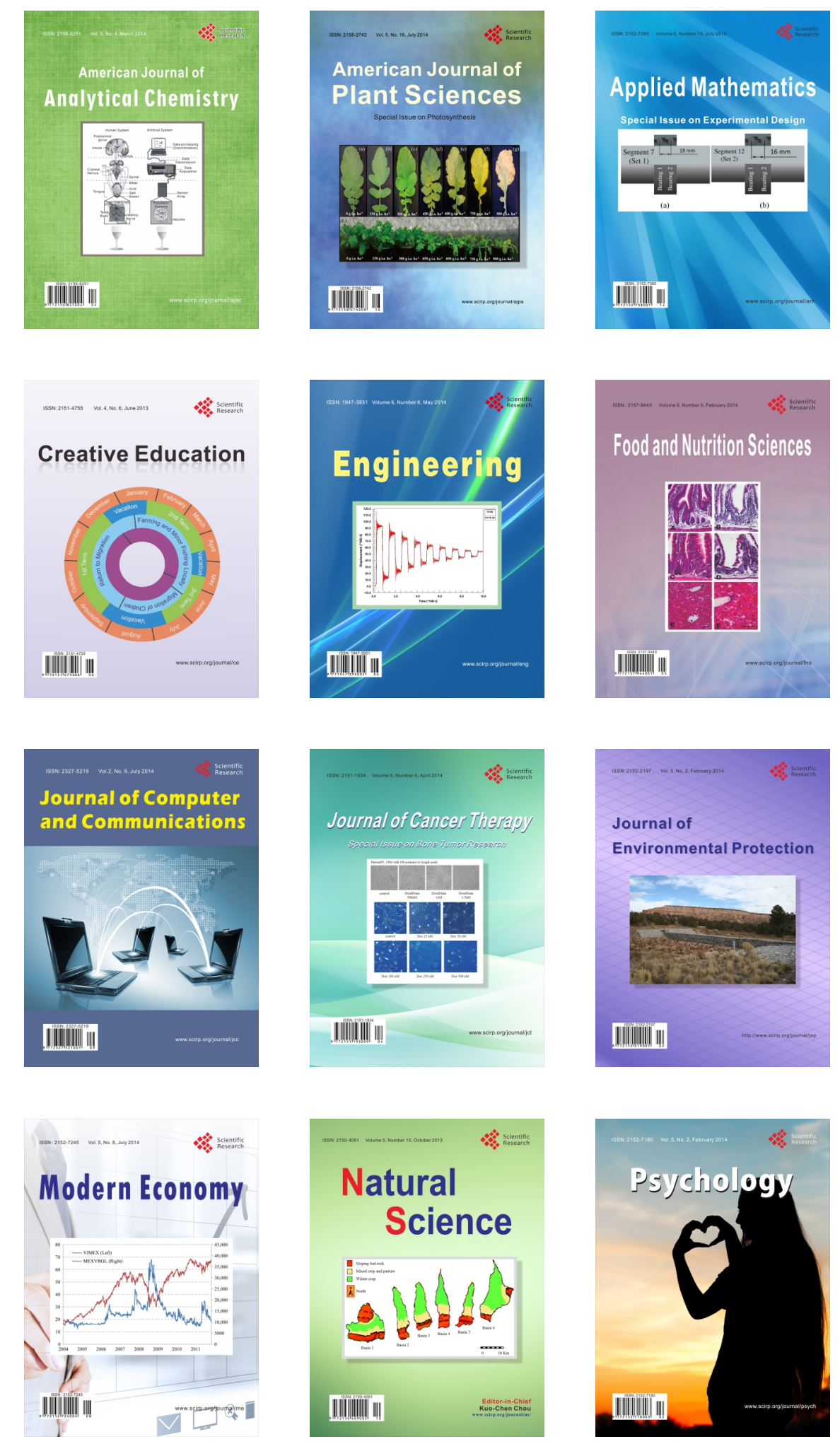